\title{
Spin-Spin Relaxation Time to Evaluate Degradation of HIPS/Organoclaynano Composites by Aging
}

\author{
Paulo Sergio Rangel Cruz da Silva, Gisele Cristina Valle Iulianelli, Maria Inês Bruno Tavares \\ Instituto de Macromoléculas Professora Eloisa Mano-IMA,Universidade Federal do Rio de Janeiro-UFRJ, Rio de Janeiro-RJ, \\ Brasil \\ Email: rangel@ima.ufrj.br, gisele@ima.ufrj.br, mibt@ima.ufrj.br
}

How to cite this paper: Silva, P.S.R.C., Iulianelli, G.C.V. and Tavares, M.I.B. (2017) Spin-Spin Relaxation Time to Evaluate Degradation of HIPS/Organoclaynano Composites by Aging. Materials Sciences and Applications, 8, 342-350.

https://doi.org/10.4236/msa.2017.85023

Received: April 6, 2017

Accepted: May 22, 2017

Published: May 25, 2017

Copyright $\odot 2017$ by authors and Scientific Research Publishing Inc. This work is licensed under the Creative Commons Attribution International License (CC BY 4.0).

http://creativecommons.org/licenses/by/4.0/

\begin{abstract}
NMR relaxometry is one of the techniques that allow observing changes in the molecular mobility that come from materials' morphology. $\mathrm{T}_{1} \mathrm{H}$ has been used to monitor food and polymer sciences. However, $\mathrm{T}_{2} \mathrm{H}$, although being a revealing as $\mathrm{T}_{1} \mathrm{H}$, is rarely used to analyze changes in thermoplastic systems it is more sensitive to the mobile region. High Impact Polystyrene nanomaterials were prepared through solution casting and were exposed for different times to UV light in the air. The samples, removed after each exposure interval, were characterized by $\mathrm{T}_{2} \mathrm{H}$, focusing on the changes in the relaxation data. The results for this parameter showed that the changes in the relaxation data come from the competition of chain scission and chain recombination processes, which occurs due to the UV light influence with increased time. The $\mathrm{T}_{2} \mathrm{H}$ data indicated that the clay ratio can influence the chain degradation processes, acting to inhibit or accelerate the aging process [1] [2].
\end{abstract}

\section{Keywords}

Degradation, High Impact Polystyrene, Nanocomposites, Relaxometry, Spin-Spin

\section{Introduction}

Evaluation of the aging process of nanostructured materials by spectroscopic analysis is of great value to understand the chemical changes caused during aging, which influence the chemical and mechanical behavior of these materials [3]-[11]. Some studies of hybrid systems composed by polystyrene (PS) and montmorillonite have been carried out. In one of them, the authors prepared nanomaterials using PS/Cloisite15A by melt processing and monitored the 
chemical changes caused by exposure to ultraviolet (UV) light $(\lambda>300 \mathrm{~nm})$ for up to 216 hours by FTIR spectroscopy. They concluded that the clay acts as a catalyst and promotes the degradation of this nanomaterial [12].

Proton spin-spin relaxation time is not commonly used to probe changes in polymer systems, because in the solid-state the $\mathrm{T}_{2} \mathrm{H}$ is very short, and it makes hard to get much information with narrow variation between samples. Meantime, few studies have been published using these relaxation measurements to evaluate polymers, especially the degradation process of polymer nanocomposites. Therefore, we decided to measure this relaxation parameter to show how it can give good information about degradation changes.

The proton spin-spin relaxation time was measured to evaluate the changing in the intermolecular interactions and molecular mobility in the materials before and after being submitted to aging. This parameter is very useful to observe changes in the mobile phase, like in rubbers, which in this case can be directly related to the degradation process, whereas the scission of chains improves their molecular mobility and promotes a recombination processes. Both promote changes in the spin-spin relaxation time values. One of the pulse sequences that can be used to measure the spin-spin relaxation time is the Carr-Purcell-Meiboom-Gill (CPMG) sequence, which allows measuring this parameter for different nuclei (here the hydrogen nucleus). The experiment used to measure of spin-spin relaxation time involves rotation of the proton magnetization from its stationary equilibrium state to a direction perpendicular or transverse to the external magnetic field $\mathrm{B}_{0}$, followed by return to equilibrium, during which the material undergoes two well-differentiated relaxation processes [13] [14] [15] [17].

Spin-spin $\left(\mathrm{T}_{2} \mathrm{H}\right)$ relaxation time measurements are generally used to identify the heterogeneity of polymer materials containing domains with size of about $\sim 25$ to $>50 \mathrm{~nm}$, thus, providing information on domain size of polymer systems. This analysis can also permit the identification of the molecular motions, which modulate the intermolecular interactions resulting in changes of the proton relaxation times. In the solid state an increment in the spin-spin relaxation time means that the molecular mobility is reduced, as demonstrated in Figure 1 [11] [12] [13]. This feature makes this technique suitable to analyze the molecular dynamics of polymer systems, especially nanocomposites. An important advantage of relaxometry is that a nondestructive method which enables analyzing the sample in intact forms [17] [18] [19] [20].

The main objective of this work was to evaluate the influence of clay addition on the degradation process of High Impact Polystyrene/organoclay systems, prepared by solution casting, submitted to aging, through the proton spin-spin relaxation time parameter. The High Impact Polystyrene is a polymer based in polystyrene (PS) with addiction of synthetic rubber, polybutadiene (PB) to improve the impact property and photodegraded process could be promoted a preferred oxidation of PB phase, reduction of molar mass, decrease in mechanical properties such as maximum elongation, tensile strength [22]. 


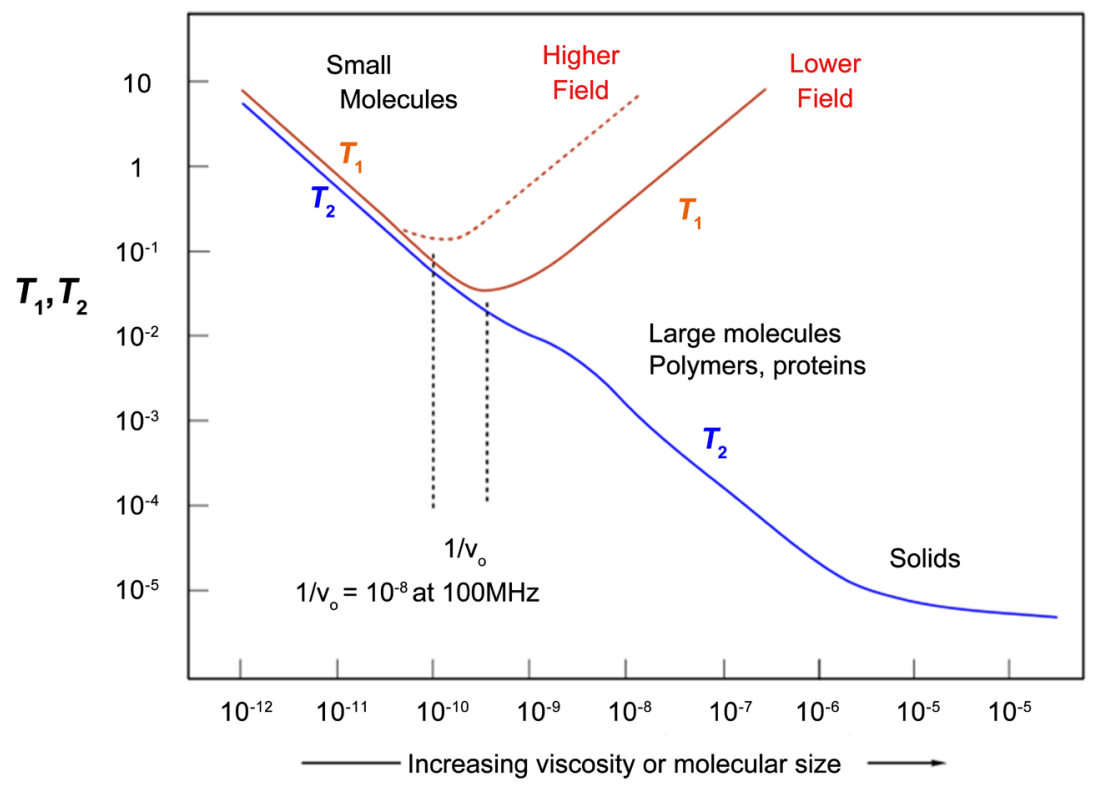

Figure 1. Tendency of $\mathrm{T}_{1} \mathrm{H}$ and $\mathrm{T}_{2} \mathrm{H}$ values as a function of molecular size and increase viscosity (adapted from Reich, H. J, 2017) [21].

The proton spin-spin relaxation time was chosen because as far as we know it has not been used to evaluate nanomaterials, especially in studies around aging processing and thermoplastic polymers. There are several works related to elastomers that evaluate changes of these materials by spin-spin relaxation time, probably due to the sensibility and also because of the materials high molecular mobility [23] [24].

The spin-spin relaxation time is more sensitive to changes than $T_{1} H$, and during the aging process the molecular dynamic of chains changes. These changes can be detected by the changes in values relaxation time and also in the domain curve distribution.

\section{Materials and Methods}

\subsection{Materials}

ViscogelS7, modified with DMBHTA, was acquired from Bentec-Laviosa S.A., and was used as received. High-impact polystyrene in pellet form was received from Innova S.A. It contains 5\% polybutadiene by weight and has glass transition temperature of $98^{\circ} \mathrm{C}$. The solvents chloroform and toluene were obtained from TediaBrazil and their quality degree was P.A.

\subsection{Nanocomposite Preparation}

Polymer solubilization was carried out in a $250-\mathrm{mL}$ Erlenmeyer flask with $50 \mathrm{~mL}$ of chloroform and $100 \mathrm{~mL}$ of toluene by mechanical stirring for $24 \mathrm{~h}$. The desired amount $(1,2$ or $3 \mathrm{wt} \%)$ of ViscogelS7 was weighed and dispersed in $50 \mathrm{~mL}$ of chloroform by mechanical stirring for $24 \mathrm{~h}$. After obtaining a homogeneous mixture, the clay dispersion was poured into the polymer solution and the obtained dispersion was stirred for a further $24 \mathrm{~h}$. Afterward, the resulting mixture 
was placed in Petri dishes (150 mm diameter), which were then placed in an oven for $24 \mathrm{~h}$ at $\sim 40^{\circ} \mathrm{C}$ to remove the solvents and to generate the films. High Impact Polystyrene films were also obtained as described above without adding the ViscogelS7 in order to compare the obtained materials. The samples were named considering the polymer and pair of solvents used (HTC), and the proportion of organoclay used varied from 0 to $3 \mathrm{wt} \%$ (HTC0, HTC1, HTC2 and HTC3) [25].

\subsection{Aging Test}

The films obtained were cut with length of $1.5 \mathrm{~cm}$, height of $6 \mathrm{~cm}$ and variable widths of approximately $0.33 \mathrm{~cm}$. All the films were measured in three points by micrometer tool and the samples were subjected to ultraviolet radiation with wavelength of $340 \mathrm{~nm}$ emitted by a xenon lamp in a chamber with air circulation (Q-SUN Xenin Test Chamber), at times from zero to 400 hours, with intervals of 100 hours between each withdrawal, following the procedure described in ASTM G155 (1999).

\subsection{NMR Relaxation Measurements}

The ${ }^{1} \mathrm{HNMR}$ spin-spin relaxation measurements were performed in a Maran Ultra 23 low-field NMR spectrometer, operating at $23.4 \mathrm{MHz}$ (for protons) and equipped with an $18-\mathrm{mm}$ variable temperature probe, operating at $300 \mathrm{~K}$. Proton spin-spin relaxation time $\left(\mathrm{T}_{2} \mathrm{H}\right)$ was measured by Carr-Purcell-Meiboom-Gill (CPMG) pulse sequence and the values of this parameter were determined [10]. The CPMG was carried out using $100 \mu$ s of $\tau$, with 4096 scans and $5 \mathrm{~s}$ as recycle delay. The obtained data were processed using the Winfit program and the WinDXP software, both of which come with the equipment.

\section{Results and Discussion}

The spin-spin relaxation time is a parameter that is sensitive to fast movements, as is spin-lattice relaxation time, but $\mathrm{T}_{2} \mathrm{H}$ is much shorter than $\mathrm{T}_{1} \mathrm{H}$ in solids. Generally speaking, a uniform relaxation value means that the sample is homogeneous, while variable values of this parameter are produced by heterogeneous structures.

The spin-spin relaxation data were analyzed focusing on two situations: one related to the increase of clay proportion while maintaining aging time constant (Table 1) and the second one keeping a fixed clay proportion while varying the aging time (Table 2). To analyze the effect of the last parameter, the tendency of spin-spin values was also plotted, as shown in Figure 2 and Figure 3.

Table 1 presents the values of proton spin-spin relaxation time for HTC samples before and after being submitted to the aging process, while Figure 2 shows the tendency of each process.

Before submitting the samples to aging, the spin-spin relaxation time for the hydrogen nucleus did not change, indicating that the samples' molecular behavior did not change with the clay proportion, as seen in Graphic 1. 
Table 1. Effect of clay ratio on proton spin-spin relaxation time as a function of aging time.

\begin{tabular}{lccccc}
\hline & \multicolumn{5}{c}{$\mathrm{T}_{2} \mathrm{H}(\mathrm{ms})( \pm 2 \%)$} \\
\cline { 2 - 6 } SAMPLES & $\mathbf{0 h}$ & $\mathbf{1 0 0 h}$ & $\mathbf{2 0 0 h}$ & $\mathbf{3 0 0 h}$ & $\mathbf{4 0 0 h}$ \\
\hline HTC00 & 16 & 55 & 78 & 80 & 81 \\
HTC01 & 12 & 28 & 61 & 92 & 80 \\
HTC02 & 15 & 56 & 80 & 84 & 80 \\
HTC03 & 13 & 93 & 82 & 77 & 94 \\
\hline
\end{tabular}

Table 2. Effect of aging time on $\mathrm{T}_{2} \mathrm{H}$ of each clay ratio

\begin{tabular}{ccccc}
\hline \multicolumn{5}{c}{$\mathrm{T}_{2} \mathrm{H}(\mathrm{ms})( \pm 2 \%)$} \\
\hline Aging Time (h) & HTC00 & HTC01 & HTC02 & HTC03 \\
0 & 16 & 12 & 15 & 13 \\
100 & 55 & 28 & 56 & 93 \\
200 & 78 & 61 & 80 & 82 \\
300 & 80 & 92 & 84 & 77 \\
400 & 81 & 80 & 80 & 94 \\
\hline
\end{tabular}

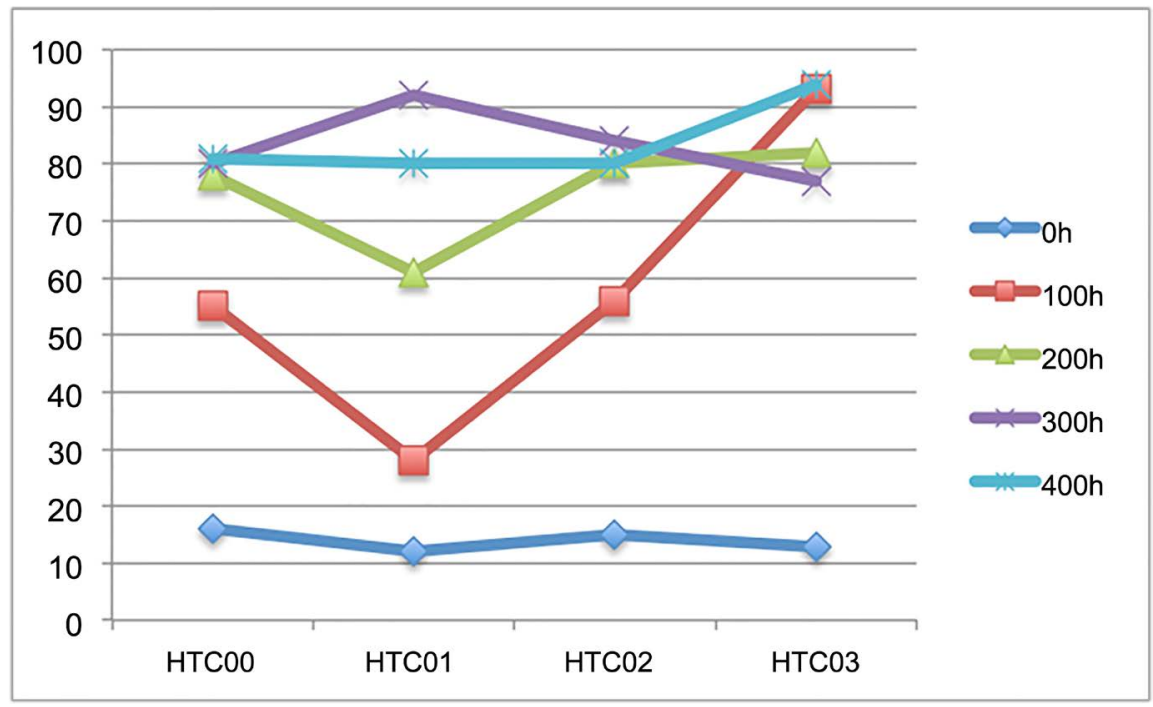

Figure 2. Tendency of $\mathrm{T}_{2} \mathrm{H}$ values as a function clay ratio (Table 1).

After aging for 100 hours, the pure polymer and sample HTC02 presented the same average $T_{2} \mathrm{H}$ value, indicating this clay proportion generated morphology in the polymer matrix that is not affected by aging action in relation to the molecular mobility behavior. However, samples HTC01 and HTC03 presented distinct behaviors, due to the difference in morphology and clay distribution in the matrix, in comparison with HTC02. Sample HTC01less degraded, demonstrating possible protection of the clay from UV radiation, characteristic of exfoliated morphology, while in $\mathrm{HTC} 03$ the action of the UV radiation was stronger, causing greater degradation, characteristic of intercalated morphology. That beha- 
vior can possibly be explained by refraction of the UV rays by the clay layers, causing them to spread within the matrix, similar to what happens with visible light, causing loss of transparency in systems containing nanoclay.

After exposure for 200 hours in the aging chamber, samples HTC00, HTC02 and $\mathrm{HTC} 03$ showed the same average $\mathrm{T}_{2} \mathrm{H}$ value, indicating that with the addition of the respective clay proportions, the morphology and distribution obtained is not affected by action of UV radiation on the matrix. However, a protective effect characteristic of exfoliated morphology was noted in sample HTC01 for aging time up to $200 \mathrm{~h}$.

After aging for 300 hours, no significant alterations were noted in the molecular mobility of samples HTC00, HTC02 and HTC03. However, the molecular mobility increased in sample HTC01 as indicated by higher $\mathrm{T}_{2} \mathrm{H}$ value, suggesting that at this proportion the prolonged action of the nanoparticle contributed to break the polymeric chains.

Finally, after accelerated aging for 400 hours, the $\mathrm{T}_{2} \mathrm{H}$ values of samples HTC00, HTC01 and HTC02 were the same. This behavior demonstrates that with these percentages, the aging effect was more pronounced than the morphology formed by the addition of clay. For sample HTC03, the molecular mobility increased in relation to the other samples.

Table 2 exhibits the effect of the clay ratio in relation to the aging time and Figure 3 shows the tendency of aging time on $\mathrm{T}_{2} \mathrm{H}$ behavior.

The relaxation time $\mathrm{T}_{2} \mathrm{H}$ of sample $\mathrm{HTC} 00$ increased progressively with aging time. This increase can be explained by the increased molecular mobility of the chains and indicates a probable scission of the chain by the action of the UV light, allowing more freedom for movement of smaller chains.

Sample HTC01 presented different behavior due to the presence of the clay, which protected the polymer matrix from the action of UV light up to 200 hours. After exposure for 300 hours, the system reached maximum molecular mobility, possibly due to changes in the clay distribution, generated by scission

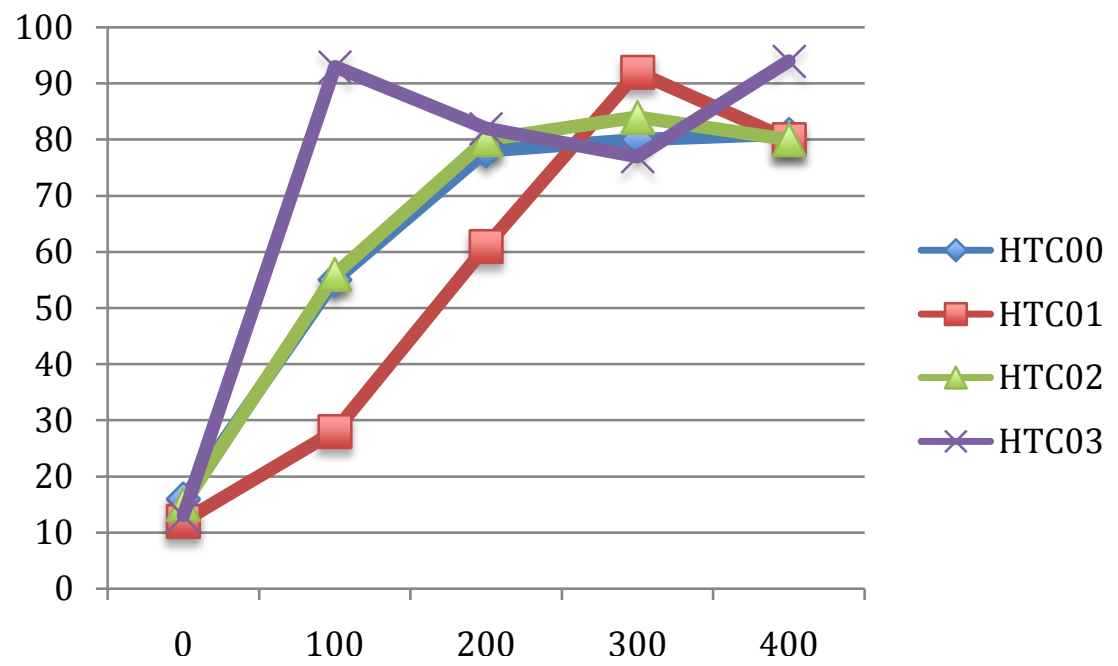

Figure 3. Tendency of spin-spin relaxation time as a function of aging time on $\mathrm{T}_{2} \mathrm{H}$, as reported in Table 2. 
of the chains of the polymer matrix, which altered the orientation of the clay layers in the matrix. After 400 hours, the molecular mobility decreased due to new interactions between the components of the nanocomposites or recombination of chains.

Sample HTC02 initially presented a progressive increase in molecular mobility, reaching a plateau between 200 and 400 hours, during which the clay did not have a significant influence.

In sample HTC03, an abrupt increase in molecular mobility was observed, demonstrating the photo-degenerative character of the system containing $3 \%$ clay in function of its distribution in the matrix. We also observed a random molecular dynamics behavior with increased exposure time, suggesting that the processes of scission and recombination of chains occurred in parallel.

\section{Conclusions}

The $\mathrm{T}_{2} \mathrm{H}$ relaxation time measurements provided important information, such as the effect of aging time and clay proportion, to the degradation process of nanostructured materials prepared with High Impact Polystyrene and organoclay through solution casting.

In the nanostructured materials, the results indicated that the clay can act to inhibit or promote the action of the aging process according to the clay concentration and the structure formed with the nanoparticles and polymer matrix. Addition of $1 \%$ of clay acted to protect the High Impact Polystyrene system up to 200 hours of aging, after which it acted as a catalyst. The samples containing $2 \%$ clay showed the same behavior as the matrix, with slight effect of aging time. Clay at the concentration of 3\% acted as a catalyst and revealed the existence of two competitive mechanisms: scission and recombination, from materials exposed from 100 and 400 hours to UV.

Regarding to UV exposure, the $\mathrm{T}_{2} \mathrm{H}$ values increased with increasing aging time, indicating that the scission process occurs over time. The maximum scission occurred with 300 hours of aging, proved by the changes in the molecular domain.

Finally, the measurement of spin-spin relaxation proved to be an effective way to show the changes in the molecular dynamics also in thermoplastic nanomaterials during the aging process.

\section{Acknowledgements}

We thank CNPq, CAPES, FAPERJ and PETROBRAS for the financial support of this work.

\section{References}

[1] Santos, F.A. and Tavares, M.I.B. (2014) Development and Characterization of Hybrid Materials Based on Biodegradable PLA Matrix, Microcrystalline Cellulose and Organophilic Silica. Polímeros, 24, 561-566. https://doi.org/10.1590/0104-1428.1653

[2] Santos, F.A. and Tavares, M.I.B. (2013) Preraring Films from Poly(Lactid Acid) and Microcrystalline Cellulose and Characterization. Polímeros, 23, 229-235. 
[3] Kumar, V. and Singh, A. (2013) Polypropylene Clay Nanocomposites. Reviews in Chemical Engineering, 29, 439-448. https://doi.org/10.1515/revce-2013-0014

[4] Bayram, I.G.J., Oral, A. and Kamil, F. (2013) Synthesis of Poly(Cyclohexene Oxide)Montmorillonite Nanocomposite via in Situ Photoinitiated Cationic Polymerization with Bifunctional Clay. Journal of Chemistry, 2013, Article ID: 617498. https://doi.org/10.1155/2013/617498

[5] ASTM E2456-06 (2012) Standard Terminology Relating to Nanotechnology. ASTM International, West Conshohocken, PA. www.astm.org

[6] Silva, P.S.R.C. and Tavares, M.I.B. (2013) Intercalação por Solução de Poliestireno de Alto Impacto em Montmorilonita Organofílica-Obtenção e Caracterização. Polímeros Ciência e Tecnologia, 23, 644-648. https://doi.org/10.4322/polimeros.2013.047

[7] Kusmono, Wildan, M.W. and Mohd Ishak, Z.A. (2013) Preparation and Properties of Clay-Reinforced Epoxy Nanocomposites. International Journal of Polymer Science, 2013, Article ID: 690675.

[8] Huskić, M., Žigon, M. and Ivanković, M. (2013) Comparison of the Properties of Clay Polymer Nanocomposites Prepared by Montmorillonite Modified by Silane and by Quaternary Ammonium Salts. Applied Clay Science, 85, 109-115.

[9] Delbem, M.F., Valera, T.S., Valenzuela-Diaz, F.R. and Demarquette, N.R. (2010) Modification of a Brazilian Smectite Clay with Different Quaternary Ammonium Salts. Quimica Nova, 33, 309-315.

[10] Rasmussen, K., Grampp, G., Eesbeek, M.V. and Rohr, T. (2010) Thermal and UV Degradation of Polymer Films Studied in Situ with ESR Spectroscopy. ACS Applied Materials \& Interfaces, 2, 1879-1883. https://doi.org/10.1021/am100219z

[11] Yang, Y., Hu, C., Zhong, H., Chen, X., Chen, R. and Yam, K.L. (2016) Effects of Ultraviolet (UV) on Degradation of Irgafos 168 and Migration of Its Degradation Products from Polypropylene Films. Journal of Agricultural and Food Chemistry, 64, 7866-7873. https://doi.org/10.1021/acs.jafc.6b03018

[12] Remili, Y.G.C., Kaci, M., Kachbi, S. and Bruzaud, S. (2009) Photo-Oxiadation of Polystyrene/Clay Nanocomposites under Accelerated UV Exposure: Effect on the Structure and Molecular Weight. Journal of Applied Polymer Science, 112, 28682875. https://doi.org/10.1002/app.29806

[13] Bovey, F.A. and Mirau, P.A. (1996) NMR of Polymers. Academic Press, Cambridge, MA.

[14] Komoroski, R.A. (1986) High Resolution NMR Spectroscopy of Synthetic Polymers in Bulk. VCH Publishers, Weinheim.

[15] McBrierty, V.J. and Packer, K.J. (2006) Nuclear Magnetic Resonance in Solid Polymers. Cambridge University Press, Cambridge.

[16] Levitt, M.H., Grant, D.M. and Harris, R.K. (2002) Encyclopedia of Magnetic Resonance. John Wiley and Sons, Hoboken.

[17] Monteiro, M.S.S.B., Neto, R.P.C., Santos, I.C.S., Silva, E.O. and Tavares, M.I.B. (2012) Inorganic-Organic Hybrids Based on Poly( $\varepsilon$-Caprolactone) and Silica Oxide and Characterization by Relaxometry Applying Low-Field NMR. Materials Research, 15, 825-832.

[18] VanderHart, D.L., Asano, A. and Gilman, J.W. (2001) Solid-State NMR Investigation of Paramagnetic Nylon-6 Clay Nanocomposites. 1. Crystallinity, Morphology, and the Direct Influence of $\mathrm{Fe}^{3+}$ on Nuclear Spins. Chemistry of Materials, 13, 37813795. https://doi.org/10.1021/cm0110775

[19] Xu, B., Leisen, J. and Beckham, H.W. (2014) Nanoparticle Dispersion in Polymer 
Nanocomposites by Spin-Diffusion-Averaged Paramagnetic Enhanced NMR Relaxometry. Nanoscale, 6, 1318-1322. https://doi.org/10.1039/C3NR04570F

[20] Almeida, A.S., Tavares, M.I.B., Silva, E.O., Neto, R.P.C. and Moreira, L.A. (2012) Development of Hybrid Nanocomposites Based on PLLA and Low-Field NMR Characterization. Polymer Testing, 31, 267-275.

[21] Reich, H.J. (2017) 8.1 Relaxation in NMR Spectroscopy. Chem.wisc.edu. https://www.chem.wisc.edu/areas/reich/nmr/08-tech-01-relax.htm

[22] Vilaplana, F., et al. (2011) NMR Relaxation Reveals Modifications in Rubber Phase Dynamics during Long-Term Degradation of High-Impact Polystyrene (HIPS). Polymer, 52, 1410-1416.

[23] Numata, K., Kurokawa, H., Kawaguchi, S., Sekine, S., Nakazawa, Y. and Asano, A. (2016) Evaluation of Sealability for Aged Rubber Seals by Spin-Spin Relaxation Time. Polymer Testing, 49, 147-155.

[24] Kulagina, T.P., Karnaukh, G.E. and Smirnov, L.P. (2015) Characterization of Structure and Self-Diffusion of Elastomers by NMR Method. Acta Physica Polonica A, 127, 1128-1132. https://doi.org/10.12693/APhysPolA.127.1128

[25] Silva, P.S.R.C. and Tavares, M.I.B. (2015) Solvent Effect on the Morphology of Lamellar Nanocomposites Based on HIPS. Materials Research, 18, 191-195. https://doi.org/10.1590/1516-1439.307314

\section{Submit or recommend next manuscript to SCIRP and we will provide best} service for you:

Accepting pre-submission inquiries through Email, Facebook, LinkedIn, Twitter, etc. A wide selection of journals (inclusive of 9 subjects, more than 200 journals)

Providing 24-hour high-quality service

User-friendly online submission system

Fair and swift peer-review system

Efficient typesetting and proofreading procedure

Display of the result of downloads and visits, as well as the number of cited articles

Maximum dissemination of your research work

Submit your manuscript at: http://papersubmission.scirp.org/

Or contact msa@scirp.org 